$136 \cdot 5]$

\title{
FORUM
}

\section{To Save the Profession: Unionize!}

PMLA invites members of the association to submit letters that comment on articles in previous issues or on matters of general scholarly or critical interest. The editor reserves the right to reject or edit Forum contributions and offers the PMLA authors discussed in published letters an opportunity to reply. Submissions of more than one thousand words are not considered. The journal omits titles before persons' names and discourages endnotes and works-cited lists in the Forum. Letters should be e-mailed to pmlaforum@mla.org.

\author{
To THE EDITOR:
}

When discussing graduate student unionization with one of my dissertation advisers, specifically her experience forming a graduate student union in the 1990s, I asked what sort of labor theory she thought would be most useful for my own efforts, to which she responded, "You don't need theory, you need practice." At first, I was a little shocked. Of course I understood at once what she meant, but here was a senior professor of English, who had spent the last two years assigning me hundreds of monographs to read, telling me that, in terms of unionizing, forget the books, just get those cards signed.

That instruction chimes nicely with Pardis Dabashi's central message in her introduction to the "Cultures of Argument" cluster of essays, as well as the message of many of those essays, perhaps best conveyed by Dabashi's injunction to be "modest" ("Introduction to 'Cultures of Argument': The Loose Garments of Argument"; vol. 135, no. 5, Oct. 2020, p. 946). The reason I find the argument so compelling is not what it says explicitly but that the modesty she promotes allows a further, more necessary logical step. The call for modesty frees us from the incredible pressure put upon scholarship by the method wars and the postcritique forums: that the fate of the profession lies principally in the theories we produce. Not only is Dabashi right that "critical argumentation" is a "deeply vexed, vulnerable act, which holds within it both the promise of becoming less professionally vulnerable and the danger of doing so at the cost of others," but her insight allows a questioning of whether arguments themselves can sink or save the discipline of literary studies writ large (948).

In other words, what frustrates me about the war of the critiques is that both sides seem to rest on an unspoken premise that somehow our scholarship alone can rescue us from precarity. Dabashi names and relieves the added weight scholarship takes on by needing to address the profession's economic crises: she diagnoses how "noxious" the debates have become and proposes a better future of critical "generosity" (947, 954). But here and elsewhere, I'm always waiting for the turn that says we are workers like all other workers, and so if we want better working conditions we should simply organize. Leaving that unsaid, there's something immodest about the idea that the way we write will save us

(C) 2021 The Author(s). Published by Cambridge University Press on behalf of the Modern Language Association of America

PMLA 136.5 (2021), doi:10.1632/Soo30812921000432 809 
from neoliberal austerity (a premise all sides, including some of the cluster's contributors, seem to take for granted to some degree, though Dabashi less so than most).

As a counterexample and a way forward, Dabashi offers the analogy of lawyers building on each other's precedents instead of constantly proposing novelty as this discipline does. But consider yet another thought experiment: the Marxist chemist. First, notice the way their citations "fortify themselves with allies" in the "fiercest of disputes," in the words of Bruno Latour, but that's par for the course in scientific literature, as he explains (Science in Action: How to Follow Scientists and Engineers through Society; Harvard UP, 1987, pp. 25, 45). Those disputes never seem as "noxious," in the way Dabashi describes, as many of ours. Why, then? Well consider this chemist: Would you know they were a Marxist by reading their papers or visiting their lab? Would it follow from a characteristic of their titrations or the style of their prose? Probably not. (The same, perhaps, with Yoon Sun Lee's narratology ["Adding versus Arguing: Narratology and Taxonomy"; vol. 135, no. 5, Oct. 2020, pp. 982-88].) Maybe when debates get heated they get personal, but do the technical disputes intervene in the political fate of the discipline itself? You might know that chemist's politics, of course, by other of their efforts in the lab; the chemist can collect as many union cards, and fight as hard on the picket line, as the literary scholar can.

I do not mean to say that literary scholarship does not or should not effect political ends. But from where I sit, those ends align so very poorly with the fight to save our jobs. Eric Hayot's essay "Then and Now" helps here when he explains how the cyclical patterns of theoretical trends, professional careers, and presidential administrations are all out of sync (Critique and Postcritique, edited by Elizabeth S. Anker and Rita Felski, Duke UP, 2017, pp. 279-95). The affordances of a scholarly monograph and union card diverge not just in the time it takes them to work-the former sometimes over decades, while the latter expires in months-but on whom they work, where, and how.

Consider, finally, the case of Julia Brown, denied tenure by Boston University in 1981 despite an impeccable record. After a decade of legal battles, the United States Supreme Court ordered she be granted tenure and hundreds of thousands of dollars in compensation because she had proved the denial resulted from endemic administrative sexual discrimination. But Brown leveled another charge against the university as well, though on this count she did not win: that her denial of tenure also resulted from discrimination based on her union efforts. Because in the spring of 1979, during the very years Brown was fighting for her own career in the ways assistant professors must, she was waving a picket sign outside the president of the university's office, standing in solidarity with her colleagues, librarians, clerical workers, and graduate students in what may be the closest thing to a general strike at a private university in American history.

All of which is to say, I agree with Dabashi and the other "Cultures of Argument" authors that we ought to hold our arguments more loosely-so that if we want to save our profession our hands are free to hold our picket signs more tightly.

Max Laitman Chapnick Boston University

\section{Reply:}

I am very grateful to Max Chapnick for his letter concerning the "Cultures of Argument" cluster. He is not alone in his worry that although a revision of the ways we argue is valuable, it isn't enough to redress the labor inequities of the contemporary university. Heather Love expressed a similar concern: as a "materialist argument," she writes, the call to decenter negatively structured and combative argumentation "is oddly incomplete" ("Response"; vol. 135, no. 5, Oct. 2020 , p. 1017). In "addressing the relation between tenured and untenured scholars," she continues, "it seems to me that raw injustice is the issue, not how we argue with each other" (1019). I think Chapnick is right that the way we write won't "save us from neoliberal austerity," and that it's "immodest" to suggest that it could. While I and my fellow contributors didn't claim or imply in the "Cultures of Argument" cluster that it could, Chapnick is right that "The Loose Garments of Argument," my introduction to the cluster, did not take the argumentative turn toward unionization that he was hoping for. This is partly because organization efforts were beyond the scope of my analytic 
task at hand, which was (apart from introducing the subsequent essays) to suggest that we consider both the academic labor crisis and the "polyvalence of art" before reaching for negatively structured arguments and "rhetorics of certainty" in advancing our claims (951). The essay did not suggest that these considerations are a sufficient condition for redressing the academic labor crisis. It's possible, though, that the first one-allowing that crisis to inform our argumentative practices-is a necessary condition for achieving that aim.

Indeed, another reason that "Loose Garments" didn't mention unionization explicitly is because, for me, the significance of critical-argumentative style to coalitional work in the university is self-evident. But Erin A. Spampinato's essay in the cluster captures this interrelatedness excellently, and largely because it does take the turn that Chapnick desires. "Academic workers were never different from other workers," she writes, and this "makes me cautiously optimistic; reality is a good place to start, if one wants to build a better world. There is both freedom and power in such modesty" ("'Never Punch Down'; or, How We Disgree (Online) Now," vol. 135, no. 5, Oct. 2020, p. 968). Spampinato's essay makes explicit the relation between critical argumentation and embodied political work. She first acknowledges that for precarious academics, the abstract realm to which the world of ideas is thought to be relegated is often an aspirational ideal. "If the adjuncts, graduate students, and early-career researchers on whose labor the university increasingly runs are struggling to meet their basic needs," she writes, "then we cannot expect them to participate in a seemingly abstract critical discourse, because . . . for them that discourse is not abstract. Even polite disagreement with a senior scholar," she continues, "can feel impossible when you believe that they can influence your ability to work in the field"; it's "terrifying" when "a senior scholar disagrees with or mocks a precarious member of the community publicly" (964). Spampinato then connects the argumentative dots to the political ones. She remarks, in the vein of Kathleen Fitzpatrick's Generous Thinking (Johns Hopkins UP, 2019), that the culture of "intellectual aggression" (Bérubé, "An Audacious Argument for Modesty"; vol. 135, no. 5, Oct. 2020, p. 974) characterizing large swathes of literary studies plays to the neoliberal model of free- market competition structuring institutions of higher education, which are invested in disincentivizing their scholars from working together-politically. Humanities educators are one of the "biggest costs" of the contemporary university (Spampinato 967), the casualization of labor being a blatant example of the austerity measures taken to mitigate that cost. Thus, Spampinato claims, "despite the values or good will of particular administrators," the university does not want academics across the spectrum of institutional security and rank to "form strong political alliances." We should argue, Spampinato writes, "in ways that don't make it impossible for us to form political coalitions, collaborate, and see one another's standpoints."

I believe chances are higher that academic workers from across this spectrum will form strong political alliances against the institutional forces that subordinate them if they take a sense of shared endeavor as the basis of their scholarly pursuits. Collaboration doesn't mean agreement. In its primary definition (the way it's being used here), it simply means working together. But the way we talk to each other says a lot about how we approach that project. An expression in Persian conveys the power of language to produce different effects in the world. Translated into English, it would go something like this: "'Please have a seat,' 'Sit down,' and 'Sit your ass down' all mean the same thing." If a tenured scholar publicly and aggressively denounces the work of an untenured scholar at a conference, online, or on the critical page it's very likely that that untenured scholar will wonder how much political ground they in fact share with that tenured scholar. And this tends to hold true no matter how much the tenured scholar believes that intellectual fisticuffs are par for the course, a sign that they are working with that untenured scholar's views-taking them, as the line goes, seriously. "Please have a seat," "Sit down," and "Sit your ass down" all might mean the same thing. But (and this is the point of the saying) word choice has the power to turn one situation into a completely different one-a moment of collaborative disagreement, for instance, into one of bond-breaking disparagement. "What could be more useful to a program that relies on our not unionizing," Spampinato asks, "than our alienation from one another?" (967). Her point (and I agree with her) is 
that disagreeing well is not a matter of empty civility; it's a matter of strategy.

Chapnick is right. But Spampinato is right, too, I think, that argumentative style and political ally-ship are often not fully distinct from each other. The way we talk to and write about one another will very likely inform how much we do or do not consider ourselves fellows in the struggle to build a better world.

Pardis Dabashi

University of Nevada, Reno 